\title{
Variability by Individual Student Characteristics of Student Satisfaction with Promising International Student Teaching Practices
}

\author{
Clayton Smith, George Zhou, Michael Potter, Deena Wang, Miranda Pecoraro, Renan Paulino \\ University of Windsor, Canada
}

\begin{abstract}
This paper explores promising teaching practices for teaching linguistically and culturally diverse international students by identifying the teaching practices that have high levels of international student satisfaction and student perceptions of learning. Data were collected through an online survey at a mid-sized Canadian public comprehensive university. Variability of student satisfaction by individual student characteristics (e.g., level of study, year of study, age, gender, field of study, country of origin, length of time studying outside country of origin, parents' educational level, and study location) is presented. Recommendations for professional practice are discussed along with potential areas for further research.
\end{abstract}

\section{Introduction}

Colleges and universities in North America are increasingly becoming ethno-culturally and linguistically diverse which is partially due to increasing enrollment of international students. Currently, 1.4 million international students choose to study at Canadian and U.S. postsecondary educational institutions, which increased by 7.1 percent between 2015 and 2016 [1,2].

While campus internationalization initiatives currently focus on areas external to the institution, such as education abroad, student exchange, recruiting international students, and institutional partnerships, there is growing interest in developing academically-related internationalization initiatives. Many institutions are increasing faculty engagement in internationalization efforts. One of the ways faculty can enhance campus internationalization is through the use of promising teaching practices for teaching international students. However, few instructors have received formal training for intercultural learning or inclusive education [3].

This article will explore the promising teaching practices for teaching linguistically and culturallydiverse international students through identifying variability by individual student characteristics of student satisfaction with the promising international student-teaching practices. The authors hope that faculty who engage in these teaching practices will become more engaged in campus internationalization and improve international student success on their campuses.

\section{Literature Review}

When moving to another country, international students face not only a different culture, which may cause a culture shock, but also academic and nonacademic challenges. These challenges can be even harder for those students who do not speak English as their first language because they have to adapt themselves to new methods of learning in a completely new language [4]. The culture clash can influence the way the learner learns the content [5]. Students' learning strategies and learning styles may vary according to their culture as they absorb learning strategies from their previous experiences [6]. We also have to take into consideration that learning styles are subject to individual preferences [7]. Culturally-diverse international students, depending on individual characteristics (e.g., gender, age, country of origin, parents' educational level, program stage, study level, length of time studying outside of their country of origin and study location), can find the learning environment to be drastically different than in their native country [8]. International students prefer the learning styles that are similar to those they used in their home country [9].

\subsection{Variabilities}

In our review of the related literature, we searched for individual student characteristics that might influence international student satisfaction and perceptions of student learning with the promising practices for teaching international students. Several student characteristics were endorsed by the literature, including gender, country of origin, age, field of study, study level, program stage, study location, parents' educational level, length of time studying outside the country of origin,

2.1.1. Gender. Kulturel-Konak, D'Allegro, and Dickinson [10] stated that there are differences in the way male and female students absorb new content. They found that male and female students have preferences for doing research and testing out 
implications, but female students tend to be able to absorb abstract learning to a greater degree than male students.

Gender is an important factor that determines students' learning styles preferences [11]. A study conducted at Shahid Beheshti University discovered possible variable influences in learning preferences among Iranian graduate students that identified the effects of the participants' gender, age, discipline, and self-rated English proficiency level along with their learning style preferences. The researchers found significant statistical variation in regards to age and gender. Results show that women prefer group-work learning styles and men have a preference for working alone [12]. Although male and female students may have differing preferred learning styles [10], cultural background is also a factor that influences those preferences [13].

2.1.2. Country of origin. International students face challenges not only because of barriers concerning communication, but also in mitigating cultural differences and discrimination [14]. These students have to adapt to a completely different culture and make a cultural transition [15]. This transition from one culture to another can affect learning development. According to Griffiths, Winstanley, and Gabriel, "These students [international] find themselves exposed to unfamiliar learning and teaching methods, bombarded by unexpected and disorienting cues and subjected to ambiguous and conflicting expectations" [16, p.275). These international students, now living in a different culture and a different learning environment, have to adjust to different styles of teaching and learning, different class formats, different forms of interaction with teachers, and different assessment criteria [4,5].

According to Rodrigues [9], students prefer learning styles that they used in their native culture. A study completed at an American university with a sample of international students from all over the world determined that the cultural background and the country of origin of participants are important factors that determine student-learning preferences [13].

2.1.3. Age. Research on whether or not age is a significant variable in determining learning preferences among international students is inconclusive. Li, Chen, Yang, and Liu [17] studied the relationship between age and learning styles among students in different nursing programs in Taiwan. They concluded that the relation between age and learning styles among nurses was almost insignificant, most likely due to the limited age range of the participants in the study ( 15 to 25 years old). A different study with theology students, designed by Cornu [18], used two samples of students over and under 40 years of age. Cornu discovered that age influenced students' answers to the questionnaire regarding their learning styles. As stated by Naserieh and Sarab, "Learning preferences may change over time as they are developmental and alter with maturity" $[12$, p.125).

2.1.4. Field of study. Studies show that learning style preferences can vary according to field of study.

A study developed with science, technology, engineering, and mathematics (STEM) and nonSTEM student majors enrolled at Penn State Berks concluded that these two groups of students learn differently [10]. The study also suggested that institutions of higher education adopt different approaches to teach these groups of students and consider the possible impact of gender.

Conversely, a study conducted at a university in Iran concluded that there was no significant relationship between the field of study and the learning styles of students [19].

Additionally, Harvey, Ling, and Shehab [20] compared the learning styles of students in engineering, mathematics, chemistry, and physicrelated majors. They found that there are differences in the learning styles among students in related fields of study. As an example, engineering students are more visually-oriented than mathematics students.

2.1.5. Parents' educational level. Parents are a fundamental factor who influence the educational success of first-generation students [21]. Families without a postsecondary history can negatively affect the first-generation student's success. "FGS [first-generation students] enroll in and earn fewer credit hours, work more hours, live off campus, participate less in out-of-class activities, and earn lower grades" [21, p.246), which results in them being more prone to failure.

First generation parents never passed through a process of being enrolled at a college or university and, due to this, they "are not able to assist their children in this major transfer from high school to the postsecondary experience" [21, p.242). Therefore, first-generation students have more chances to fail than students who have parents with higher educational experiences. The authors identify methodologies and teaching practices that teachers may employ to help this specific group of students achieve success, such as creating a sense of community among students and using illustrative examples to facilitate the learning environment, which tries to minimize the challenges suffered by first-generation students.

2.1.6. Length of time studying outside country of origin. A study with a sample of 
Korean, Chinese and Filipino students suggested that the length of time studying outside one's native country is an important factor that determines the learning preferences of a student [22]. In this study, Park concluded, "Korean, Chinese, and Filipino students are more visual than Whites" [23, p.254], but after three years of living in the U.S, they changed their learning styles and became more auditory. That is, the students adapted to the learning styles of native English speakers.

Park [23] also developed another study with Southeast Asian students (Cambodian, Hmong, Lao, and Vietnamese), in order to determine their preferred learning styles and to identify any variability that influenced their learning style preferences with regard to gender, ethnicity, and length of time residing in the United States. This research concluded that learning styles were affected by ethnicity, but did not identify any change of Southeast Asian learning styles according to duration of their stay in the U.S.

2.1.7. Study level. The learning styles preferences differ from undergraduate students to post-graduate students [24]. A study developed with undergraduate and graduate medical students revealed that undergraduate students tend to be more active learners, while graduate students are more reflective [24]. A study of English as a secondlanguage (ESL) learners [23] found that kinesthetic and tactile learning are the most preferred styles.

Fischer [25] implied that undergraduate students, compared to graduate students, require more attention. Graduate students tend to be more mature and independent. This statement allows us to deduce that the level of maturity, including the study level of the student, can contribute to the preferred learning styles [12].

2.1.8. Program stage. Differences in learning styles may vary from students in their first/secondyear to their third/last-year. One study [26] conducted at the University of Basque Country wanted to discover if there were any variation in the learning strategies used by students according to their program stage and age. The data collected proved that the variable age did not show statistical significance, but their learning strategies had changed according to their program stage [26]. Student learning strategies can possibly change over time according to their maturity level [12].

2.1.9. Study location. Tan [27] states that teaching international students on an online platform is challenging. She also suggests that professors need to adopt new practices to teach this specific group of students. International students in an online learning environment may face some initial challenges, including a change of cultural norms and the change of learning environment from a face-toface one to an online class.

A study developed at the University of Windsor in Canada involving three international students enrolled in an online master's program, researched the impacts of studying in an online environment. The researchers discovered that international students might face some challenges with regard to the change of the learning environment. The study participants presented concerns regarding the lack of interaction with peers and socialization in the online learning environment [28].

According to Nevison, Drewery, Pretti and Cormier [29], international students find their co-op work term more significant than domestic students because of the work experience gained. The researchers imply that for students in co-op programs, an engaging learning environment is required so that their "work experiences become meaningful" [29, p. 817). The researchers concluded that supervisors "should manage a learning culture that support students' learning." [29, p. 818] in order for these students to have the best learning experiences.

\section{Theory}

This study is based on the belief that the most effective teaching practices are where promising teaching practices, international student satisfaction, and student perceptions of learning meet. It is guided by Tinto's [30] student integration model, which was built on Durkheim's [31] suicide model. Tinto's model presents the notion that individual departure from postsecondary-educational institutions develops out of a lengthy process of interactions between the individual and her/his connection with institution's academic and social systems. He explained that students who achieve academic and social integration, both formal and informal, increase their commitment to their career and educational goals, and their postsecondary educational institution. Figure 1 shows how promising teaching practices, student satisfaction, and student perceptions of learning come together to create the necessary academic and social integration.

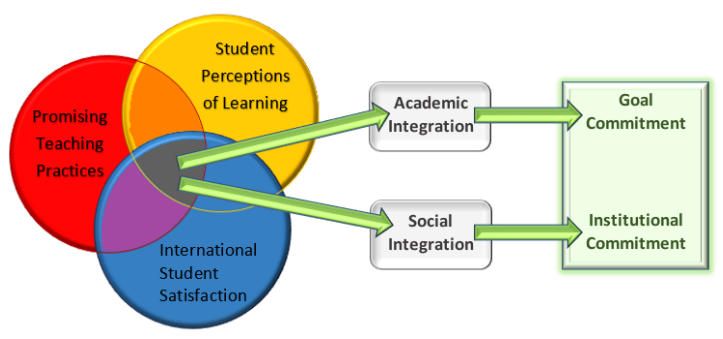

Figure 1. Identifying Effective Teaching Practices 


\section{Method}

\subsection{Research question}

The purpose of the current study was to examine multiple characteristics of linguistically and culturally diverse international students at a midsized, comprehensive public university in Canada, and to measure variability in student satisfaction and perceptions of learning of promising teaching practices according to individual attributes. The following research question guided our study:

- How do differences among international students in regard to individual student characteristics (e.g., level of study, year of study, age, gender, field of study, country of origin, length of time spent studying outside country of origin, whether parent(s) were educated to a degree level, study location) impact student satisfaction and perception of learning of the promising teaching practices?

\subsection{Participants}

Research participants were international students who study at a mid-sized, comprehensive public university in Canada. Participants were diverse, as they reported deriving from varying countries of origin, study levels, years of study, fields of study, and ages. The sample size was 3,467 international students and 1,056 respondents, resulting in a 32 percent response rate.

\subsection{Procedures}

Participants for this study were recruited to fill out an online survey questionnaire. An online (Qualtrics) survey questionnaire was administered in February 2018 to collect information about participants' satisfaction and learning associated with promising teaching practices for teaching linguistically and culturally diverse international students. The survey also collected a limited amount of demographic data so that the researchers could relate individual student characteristics with student learning preferences.

A pilot study was conducted to achieve internal validity. A panel of ten international students, representative of the local institutional student profile, reviewed the questions used in the instruments to ensure they matched their intended use. Modifications were subsequently made to the instruments.

Participants were recruited by the following methods:

- Individual e-mail invitation was sent to all international students enrolled during the
Winter 2018 semester in university-level or ESL courses;

- A mass e-mail was sent to the institution's international student list serve, which included most international students;

- A mass e-mail was sent to the institution's teaching and graduate assistant list serve;

- Social media posts were made at various institution-affiliated international studentoriented social media locations;

- Announcements were read in class by interested faculty members; and

- Verbal recommendations were made by members of international student-serving offices and departments.

A prize draw (first prize of $\$ 200$ and six $\$ 50$ second prices were given using prepaid credit cards) was used to encourage participation.

\section{Results}

Differences among individual student characteristics (e.g., study location, program stage, length of time studying outside of the country of origin, age, gender, parents' educational level, field of study) and their subsequent impact on promising teaching practices associated with high levels of student satisfaction and student perceptions of learning were examined using either analysis of variance (ANOVA) or T-Tests. Results were evaluated at a significance level of 0.05 .

Survey respondents are representative of the international student demographic at the research site institution. The respondents are ESL students (4\%), undergraduate students $(18.1 \%)$, or graduate students $(77.4 \%)$. The study levels of undergraduate respondents included ESL (4.2\%), first-year $(52.8 \%)$, second-year $(12.6 \%)$, final year $(19.9 \%)$, and other $(10.6 \%)$. Participants' ages ranged from under 18 to 54 years of age, with respondents indicating their age as under $18(0.4 \%), 18$ to 20 years $(7.5 \%), 21$ to 24 years $(57.7 \%), 25$ to 34 years $(30.3 \%)$, and 45 to 54 years $(1 \%)$. Respondents identified their gender as male $(59.6 \%)$ or female (39.1\%). Respondents study in a wide array of academic areas, including arts, humanities, and social sciences $(5.4 \%)$, business $(18.6 \%)$, education $(5.4 \%)$, ESL $(1.2 \%)$, law $(0.8 \%)$, engineering $(50.3 \%)$, human kinetics $(0.4 \%)$, nursing $(0.2 \%)$, and science $(17.6 \%)$. The majority of the respondents reported originating from one of six countries of origin, including Bangladesh (2.5\%), China $(31 \%)$, India $(45.5 \%)$, Iran $(2.7 \%)$, Nigeria $(5.4 \%)$, and Pakistan $(1.2 \%)$. Respondents reported differing lengths of time studying outside of their country of origin, with most $(50.6 \%)$ spending less than one year studying abroad. Most respondents 
(72.1\%) indicated that their parents were educated to a degree level. More than two-thirds (83\%) said their study location was on-campus.

\subsection{Level of study}

ANOVA analysis revealed that the promising teaching practices that received statistically significant responses between the groups of participants studying at the ESL, undergraduate, or graduate levels in regard to student satisfaction and student perceptions of learning were academic integrity, assessing needs, assessment, assignments, culturally responsive teaching, differentiated instruction, diversity and inclusion, group work, language proficiency, lecture design and delivery, and physical environment. Of those areas, assessing needs, assessment, culturally responsive teaching, and language proficiency received stronger $\mathrm{p}$-values (e.g., 0.000-0.010) over a greater number of teaching practices within their area compared to all other areas, which received more marginal p-values (e.g., 0.020-0.050) across a fewer number of teaching practices. However, several promising teaching practices were found to be statistically significant throughout all levels of study. This indicates that international students at varying levels of study feel differently about the use of several of the promising teaching practices, with emphasis on those associated with assessing needs, assessment, culturally responsive teaching, and language proficiency.

\subsection{Year of study}

ANOVA results showed that several promising teaching practices were found to be statistically significant throughout all areas between the groups of respondents who reported being in their first, second, final, or other year of study, or being enrolled in the ESL program. Among the 22 areas of promising teaching practices, 17 areas included statistically significant responses from students. Responses varied from marginal (0.020-0.050) to stronger (0.000-0.010) p-values. The areas that did not receive statistically significant results for several teaching practices included assessment, clarifying expectations, class preparation, communicating outside of the classroom, and reviewing material. Those areas that received the strongest $\mathrm{p}$-values included academic skills, culturally responsive teaching, differentiated instruction, and feedback. Additionally, all of the teaching practices within the diversity and inclusion area received very strong $\mathrm{p}$ values. This data suggests that international student satisfaction and perceptions of learning with regard to the promising teaching practices vary significantly depending on year of study, and these differences are the most pronounced in the area of diversity and inclusion.

\subsection{Age}

An ANOVA showed that the age of the student made less of an impact on the ways students reported their perception of and satisfaction with the promising teaching practices. Areas with teaching practices that received statistically significant responses were academic integrity academic skills, assessment, assignments, communicating outside of the classroom, feedback, language proficiency, and lecture design and delivery. However, the strength of the p-values among these areas varied considerably, and only one to two teaching practices per area yielded significant findings. Nonetheless, the areas that received the strongest $\mathrm{p}$-values $(0.000$ 0.010) were communicating outside of the classroom, culturally responsive teaching, differentiated instruction, and diversity and inclusion. These findings imply that, however slight the impact, a student's age can affect their perception of, and satisfaction with, the promising teaching practices in these areas.

\subsection{Gender}

Respondents were asked to disclose their gender identity as either "male", "female", or "other". For this T-Test, data corresponding with "other" was excluded, as very few respondents reported having a gender identity different from the ones specified. The T-Test results found that gender identity played a very small role in influencing the students' responses. The teaching practice areas that received at least one statistically significant finding were assignments, clarifying expectations, and climate in the classroom; though the p-values for the teaching practices in these areas were marginal (0.020$0.050)$. This data suggests that the gender identity of the respondents was an overall insignificant factor in determining their satisfaction associated with the promising teaching practices, as male and female identified students responded similarly to the survey.

\subsection{Field of study}

The ANOVA results that compared the responses of international students by field of study showed that the students' academic discipline contributed to their perception of and satisfaction with some of the promising teaching practices. The areas that received statistically significant responses were assessing needs, assignments, climate in classroom, communicating outside of the classroom, culturally responsive teaching, differentiated instruction, diversity and inclusion, feedback, group work, 
language proficiency, lecture design and delivery, and verbal communication--though the strength of the $p$-values in all of these areas varied greatly. The areas that included the greatest number of statistically significant $p$-values were culturally responsive teaching, diversity and inclusion, feedback, group work, and language proficiency. Therefore, the respondents' field of study had a considerable impact on the ways in which they responded to the survey.

A subsequent T-Test compared responses from students in STEM and non-STEM related fields of study. Similarly, among a handful of areas that received statistically significant responses, differences within the area of diversity and inclusion were most prominent.

\subsection{Country of origin}

ANOVA revealed that all but three promising teaching practices areas (clarifying expectations, reviewing materials, and visual communication) received statistically significant responses between survey respondents from Bangladesh, China, Iran, India, Nigeria, and Pakistan. The strength of the pvalues varied from $0.000-0.050$ in all areas, although the teaching practices within the areas of academic integrity, assessing needs, culturally responsive teaching, differentiated instruction, diversity and inclusion, group work, and language proficiency contained the most amount of teaching practices with statistically significant responses. These results suggest that, in nearly all areas, international student satisfaction and perceptions of learning varies depending on their country of origin.

\subsection{Length of time studying outside country of origin}

The results of ANOVA showed that the length of time studying outside one's country of origin affected the ways in which students responded to the survey. Between the groups of respondents who have spent less than one year, one-year, two to threeyears, and three years or more outside their home country, statistically significant responses were recorded in the areas of academic integrity, assessment, assignments, culturally responsive teaching, differentiated instruction, diversity and inclusion, lecture design and delivery, studentcentred teaching, verbal communication, and visual communication. Among these areas, diversity and inclusion and verbal communication contained the greatest number of statistically significant $\mathrm{p}$-values. Additionally, the p-values in all areas ranged from strong to weak (0.000-0.050). These findings indicate that international students studying outside their country of origin for varying lengths of time feel differently about the use of several of the promising teaching practices, with emphasis on those within the areas of diversity and inclusion and verbal communication.

\subsection{Parents' educational level}

A T-Test revealed that only four areas of promising teaching practices (assignments, communicating outside of the classroom, lecture design and delivery, and verbal communication) received statistically significant responses between first-generation university student respondents and students whose parents had been educated to a degree level. Interestingly, the perceived level of learning for all of the teaching practices within the area of communicating outside of the classroom received very strong p-values $(0.000-0.010)$. This suggests that first-generation international students feel similarly about their education, as do other international students whose parents have obtained a degree, although their preferences for communicating with their professors differ.

\subsection{Study location}

An ANOVA showed that all but four areas of promising teaching practices received statistically significant responses from international students studying on campus, student exchange, placement, co-op work term, online learning, or otherwise. For the most part, international students studying at various locations within one institution responded differently to the survey. Specifically, academic integrity, communicating outside of the classroom, and diversity and inclusion contained the greatest number of statistically significant $p$-values. The only areas that did not receive statistically significant responses were assessing needs, assessment, assignments, and class preparation. In conclusion, the learning preferences of international students studying at various locations differed in almost all areas of promising teaching practices.

\section{Discussion}

Our study verified that among international students, the level of study (ESL, undergraduate, or graduate levels) is an important factor that determined students' choices related to students' satisfaction and perception of learning of the teaching practices used by their instructors. As their learning strategies and styles vary according to the student's study level, their preferences for specific teaching practices also statistically varied. Contrarily, the variable age did not have a large impact on students' choice regarding their preferred teaching practices.

During our literature review, we discovered that the variable age in multiple studies presented 
different results in relation to the preferred learning styles used by students depending on the age range of study participants $[17,18]$; if the age range was narrow (e.g., 15 to 25 years), the results may not have achieved statistical significance, but if the age range was wider (e.g., 18 to 40 years), the results could have been more likely to show relevant significance. Our findings lead us to conclude that, for our sample of international students, age slightly influences their satisfaction and perception of learning with the promising teaching practices areas, including communicating outside the classroom, culturally responsive teaching, differentiated instruction, and diversity and inclusion areas.

The claim that there are differences in learning styles and preferences among students in varying years of study is supported by both the literature and the survey data. Year of study was found to affect student satisfaction and perceived level of learning in nearly all areas of promising teaching practices. This may be because, as suggested in the literature, learning strategies and preferences shift and adjust according to the length of time studying within a given program, field of study, or institution. International students may therefore report being more satisfied with their education at a Canadian institution the longer they study there, or they may rate their education differently due to the more experience they have studying at the post-secondary level. Although the literature suggests that students become more accustomed to the style of teaching and learning in post-secondary institutions as they advance throughout the years, our findings do not locate which group of students responded to the survey most differently. In other words, it is unknown whether learning preferences differ the most between first/second year students and final year undergraduate students, ESL students and final year undergraduate students, ESL students and first/second year undergraduate students, etc.

The survey data shows that differences in international student satisfaction and perceptions of learning are most pronounced in the area of diversity and inclusion. One possible explanation for this could be that international students in the earlier years of their program require more effort from their instructor in recognizing and encouraging culturally-framed ways of knowing or acknowledging student diversity. Based on the additional demographic information obtained about survey respondents (of which graduate students were overrepresented) and the other analyses according to individual student characteristics (i.e., length of time spent studying outside country of origin), one could conclude that international students at the beginning of their master's program abroad feel differently about their instructor's use of diversity and inclusion compared to students approaching the end of their master's program.
International students' perceptions of learning and satisfaction changed according to their country of origin. Our data showed that in almost all areas (e.g., academic integrity, academic skills, assessing needs, assessment, assignments, class preparation, climate in classroom, communication outside of the classroom, culturally-responsive teaching, differentiated instruction, diversity and inclusion, feedback, group work, language proficiency, lecture design, note taking, reviewing material, studentcentred teaching, and verbal communications) students answers varied according to country of origin.

This can be explained since international students have different learning styles in their home country, and they prefer those practices [9]. As they arrive in the new country, they need to adapt to learning and teaching strategies that are often quite different from the ones they experienced in their home country.

As found in our literature search, international students learning styles vary according to the length of time they have lived outside their country of origin. Our findings support this statement. The answers to the questionnaire varied according to the length of the time international students studied abroad. International students' preferred teaching styles may change over time. A possible explanation for that is that, as students pass through the process of acculturation and get more used to the foreign culture, such as the different teaching approaches used by their professors, they become more comfortable with the different teaching practices and more easily achieve a higher level of satisfaction and perception of learning.

Contrary to what was found in the literature, findings derived from our survey data do not support the claim that the educational level of the parents plays a significant role in influencing the learning styles and preferences of international students. In fact, only four areas of promising teaching practices received significantly different responses from firstgeneration international students and students whose parents had been educated to a degree level. Of these four areas, teaching practices that fell under the category of communicating outside of the classroom received the most varied responses between the two groups of students. Instructors who attempt to make connections with and create a sense of community among students could help to mitigate the differences in this area.

The literature suggests that first-generation university students tend to face additional challenges and are more prone to failure due to lack of guidance from parents who have not had postsecondary educational experience. While this may be true, our survey did not require students to disclose their level of academic achievement or involvement in extracurricular activities, so we are not able to make this conclusion. However, given 
that first-generation international students were generally equally satisfied with their education and level of learning as their multi-generational counterparts, one could infer that academic success between these two groups is comparable. Perhaps first-generation international students encounter a more negative postsecondary experience abroad if they enter a program with a smaller international student enrollment, fewer international students from the same country of origin, or if their culture and language are more incompatible with that of the host country.

The results from the survey data are somewhat congruent with the literature regarding international students' area of study and learning preferences. While some of the promising teaching practices received similar responses from international students across all fields of study, respondents from different academic disciplines typically reported varying levels of satisfaction and perception of learning. Although the literature suggests that field of study has no significant impact on learning styles and preferences, our data suggests otherwise. However, the literature does support the notion that learning styles and preferences vary between groups of students in STEM and non-STEM related fields. The variability in our data may be a result of differences among STEM and non-STEM students as opposed to differences among all fields of study when compared to one another. To better understand where international student preferences differ according to field of study, further research should compare the responses of STEM and non-STEM students.

The areas that received the most significant responses were culturally responsive teaching, diversity and inclusion, feedback, group work, and language proficiency. Perhaps international students who study in smaller academic disciplines with fewer international students feel differently about the use of the teaching practices in these areas compared to international students in larger programs with larger international student enrollments. For instance, an instructor who typically teaches few international students may have less of a focus on cultural sensitivity, facilitating cross-cultural communication, or providing opportunities for English language development within the curriculum.

The literature indicates that the location at which international students study, whether online, oncampus, during practica/internships or otherwise, significantly affects their feelings towards their education. For instance, it is generally agreed that international students are less satisfied with online education at Canadian universities, while they tend to value educational co-op, placement, and internship opportunities. An analysis of our survey data showed that student satisfaction and perceptions of learning varied significantly according to study location. These findings, along with the information provided by the literature, suggests that international students receive distinctly different educational experiences studying abroad depending on whether or not they engage in on-campus or off-campus learning. While our analysis does support the claim that study location affected the way in which students responded to the survey, it is unknown where, between these groups of students, differences were found. For instance, it is unknown if major differences in student satisfaction and perceptions of learning lie between online and on-campus students, placement or co-op students, etc.

Teaching practices associated with assessing needs, assessment, assignments, and class preparation were the only areas that did not receive statistically significant responses. One could infer that, since study location does not influence international student satisfaction and level of learning in these areas, these teaching practices generally maintain the same quality and value regardless of where international student learning takes place. Considering that off-campus learning may be more prevalent in certain areas of study (e.g., engineering, education), and that on-campus learning may be more prevalent in arts, humanities, and social science fields, further research that investigates learning styles and preferences between these groups could help to identify strategies to better mitigate differences in levels of satisfaction and perception of learning.

No statistical significance was found in the area of gender. Even though previous research found that gender was an important factor that determined student's learning styles and strategies $[10,11,12,13]$, our research found that gender did not affect international students' preferences for certain teaching practices, as their responses were very similar.

\section{Conclusion and Implications}

This study identified a number of potential recommendations for practice. We found that there are many teaching practices that result in both student satisfaction and student perceptions of learning in the following areas: academic integrity, assessment, assignments, clarifying expectations, communicating outside of the classroom, lecture design and delivery, verbal communications, and visual communications. Use of these teaching strategies by instructors should lead to enhanced international student success.

Variability was found for respondent level of study, year of study, field of study, country of origin, length of time studying outside the country or origin, and study location. Instructors who learn about the 
background of their students as it relates to these individual characteristics and use them as a way of modifying instruction will likely enhance international student success in their classrooms.

\section{Study Limitations and Suggestions for Future Research}

The study has some limitations that the reader should consider including:

- The response rate on the online survey was approximately two-third's graduate students, which limits what can be said about the international undergraduate student experience, except in aggregate ways.

- The perceptions of student learning data is self-reported, which makes it hard to discern how much student learning can be accurately associated with each teaching practice.

- The study was completed in the winter semester and is based on one semester of data. Research conducted for the full academic year may have created more response diversity.

More research is needed to more fully understand how undergraduate international student satisfaction and perceptions of student learning are associated with the promising teaching practices for teaching international students. In particular, we identified these areas as possible topics for future research:

- How student satisfaction with promising teaching practices varies by year of study (e.g., ESL, early undergraduate years, later undergraduate years);

- What factors (e.g., number of international students in an academic program, diversity of international students in an academic program, language compatibility with home country) impact the success of firstgeneration international students;

- Why satisfaction with promising teaching practices differs between STEM and nonSTEM students; and

- Differences between the satisfaction of international students who study on-campus and online.

\section{References}

[1] Canadian Bureau of International Education, A World of Learning: Canada's Performance and Potential in International Education, CBIE, Ottawa, 2014.

[2] Institute of International Education, Open Doors, IIE, New York, 2016.
[3] Paige R. M., and M. L. Goode, Intercultural Competence in International Education Administrationcultural Mentoring: International Education Professionals and the Development of Intercultural Competence, SAGE Publication, USA, 2009.

[4] Smith, C., G. Zhou, M. Potter, and D. Wang., "Connecting Best Practices for Teaching Linguistically and Culturally Diverse International Students with International Student Satisfaction and Student Perceptions of Student Learning", Advances in Global Education and Research, ANAHEI Publishing, LLC, Florida, USA, 2019, pp.252-265.

[5] K. D. Foster, and D. M. Stapleton, "Understanding Chinese Students' Learning Needs in Western Business Classrooms",International Journal of Teaching and Learning in Higher Education, 2012, pp. 301-313.

[6] Bandura, A., "Social Learning Theory",General Learning Press, General Learning Press, New York, 1971, pp. 1-46.

[7] A. Wintergerst, and A. DeCapua, "Exploring the Learning Styles of Russian-speaking ESL Students", The CATESOL Journal, Fountain Valley, CA ,2001, pp. 23-46.

[8] R. Koul, and D. Fisher, "Cultural Background and Students' Perception of Science Classroom Learning Environment and Teacher Interpersonal Behavior in Jammu, India",Learning Environments Research, Switzerland, 2005, pp. 195-211.

[9] C. Rodrigues, "Culture as a Determinant of the Importance Level Business Students Place on Ten Teaching/learning Techniques: A Survey of University Students",Journal of Management Development, Emerald Group Publishing Limited, Bradford, 2005, pp. 608-622.

[10] S. Kulturel-Konak, M. L. D'Allegro, and S. Dickinson, "Review of Gender Differences in Learning Styles: Suggestions for STEM Education", Contemporary Issues in Education Research, The Clute Institute, Littleton, CO, 2011, pp. 9-18.

[11] S. Lam-Phoon. "A Comparative Study of the Learning Styles of Southeast Asian and America Caucasian College Students on Two Seventh-Day Adventist Campuses",Andrews University,Michigan, 1986, pp. 1-130.

[12] F. Naserieh, and M. R. Anani Sarab, "Perceptual Learning Style Preferences among Iranian Graduate Students",System,Elsevier Ltd., Amsterdam, Netherlands, 2013 pp. 122-133.

[13] P. Rao, "Learning Challenges and Preferred Pedagogies of International Students", The International Journal of Educational Management,Emerald Group Publishing Limited, Bradford, 2017, pp. 1000-1016.

[14] C. O. DuBose, "But I Don't Understand You: One Faculty's Observations of the Challenges Facing 
International Healthcare Students",Journal of International Students, Newbury Park, CA, 2017, pp. 154159.

[15] N.E. Popadiuk, and N. M. Arthur, "Counselling International Students in Canadian Schools", International Journal for the Advancement of Counselling, Springer Nature B.V., The Hauge, 2004, pp. 125-145.

[16] D. S. Griffiths, D. Winstanley, and Y. Gabriel, "Learning Shock: The Trauma of Return to Formal Learning", Management Learning,Tanaka Business School Discussion Papers,London,Tanaka Business School, 2005, pp. 275-297.

[17] Y. S. Li, H.M. Chen, B. H. Yang, C. F. Liu, “An Exploratory Study of the Relationship between Age and Learning Styles among Students in Different Nursing Programs in Taiwan", Nurse Education Today, Elsevier Ltd., London, 2011, pp. 18-23.

[18] A. L. Cornu, "Learning Styles, Gender and Age as Influential Issues amongst Students of Theology", Journal of Beliefs \& Values, Routledge, London, 1999, pp. 110114.

[19] R. Sahragard, Y. Khajavi, and R. Abbasian, "Field of Study, Learning Styles, and Language Learning Strategies of University Students: Are there any Relations?", Innovation in Language Learning and Teaching, Routledge, London, 2016, pp. 255-271.

[20] D. Harvey, C.Ling, and R. Shehab, "Comparison of Student's Learning Style in STEM disciplines",IIE Annual Conference Proceedings, Institute of Industrial and Systems Engineers (IISE), Norcross, 2010, pp. 1-6.

[21] A. R. Unverferth, C. Talbert-Johnson, and T. Bogard, "Perceived Barriers for First-generation Students: Reforms to Level the Terrain", International Journal of Educational Reform, SAGE Publication, Newbury Park,CA,2012, pp. 238-252.

[22] C. C. Park, "Learning Style Preferences of Asian American (Chinese, Filipino, Korean, and Vietnamese) Students in Secondary Schools", Equity \& Excellence in Education, Routledge, London, 1997, pp. 68-77.

[23] C. C. Park, "Learning Style Preferences of Southeast Asian Students",Urban Education,Corwin Press, Newbury Park, CA, 2000, pp. 245-268.

[24] I. Shukr, R. Zainab, and M. H. Rana, "Learning Styles of Postgraduate and Undergraduate Medical Students", Journal of the College of Physicians and Surgeons, College of Physicians and Surgeons Pakistan, Pakistan, 2013, pp. 25-30.

[25] K. Fisher, "Colleges Adapt to New Kinds of Students from Abroad", The Chronicle of Higher Education, Retrieved from https://www.chronicle.com/ article/Colleges-Educate-a-New-Kind-of/127704
[26] A. Aizpurua, I. Lizaso, and I. Iturbe, "Learning Strategies and Reasoning Skills of University Students", Revista de Psicodidáctica,Elsevier,Espana, S.L.U, Universidad de Pais Vasco, 2018, pp. 110-116.

[27] F. Tan, "Facilitating International Chinese Students' Transformation in an Online Course",Adult Learning, SAGE Publication, Newbury Park,CA, 2018, pp. 32-34.

[28] Z. Zhang, and R. Kenny, "Learning in an Online Distance Education Course: Experiences of Three International Students", International Review of Research in Open and Distance Learning,Athabasca University, Athabaska, 2010, pp. 17-36.

[29] C. Nevison, D. Drewery, T. Pretti, and L. Cormier, "Using Learning Environments to Create Meaningful Work for Co-op Students", Higher Education Research \& Development, Routledge, London, 2016, pp.807-822.

[30] Tinto, V., Leaving College: Rethinking the Causes and Cures of Student Attrition, University of Chicago Press, Chicago, 1993.

[31] Durkheim, E., Suicide: A Study in Sociology, Routledge, London, 1951. 